\title{
Crystal structure of a new polymeric thallium-lasalocid complex: lasalocide anion-thallium(I) containing aryl-Tl interactions
}

\author{
M. Akkurt, ${ }^{a *}$ S. Öztürk Yıldırım, ${ }^{a}$ F-Z. Khardli, ${ }^{b}$ M. Mimouni, ${ }^{b}$ V. McKee, \\ and T. Ben Hadda ${ }^{b^{*}}$ \\ ${ }^{a}$ Department of Physics, Faculty of Arts and Sciences, Erciyes University, 38039 Kayseri, \\ Turkey \\ ${ }^{b}$ Laboratoire de Chimie des Matériaux, Faculté des Sciences, 60000 Oujda, Morocco \\ ${ }^{c}$ Chemistry Department, Loughborough University, Loughborough Leics LE11 3TU, UK \\ E-mail: tbenhadda@yahoo.fr; akkurt@erciyes.edu.tr
}

\begin{abstract}
The title complex, $\left[\mathrm{Tl}\left(\mathrm{C}_{34} \mathrm{H}_{53} \mathrm{O}_{8}\right)\right]_{\mathrm{n}}$, forms a pseudo individual monomer complex, in which the anionic oxygen of carboxylate group serves to neutralise the charge of $\mathrm{Tl}^{+}$, the other five $\mathrm{O}$ centres of the first lasalocid anionic ligand (Lasa 1) and in which this ligand is pentadentate Oligand and bonded to a second $\mathrm{Tl}$ centre by using phenyl-metal coordination. A second lasalocid ligand (Lasa 2) is also pentadentate O-ligand and bridges the first Tl centre within the polymer. The monomeric unit is stabilized by strong intramolecular aryl-Tl type-metal half sandwich bonding interactions.
\end{abstract}

Keywords: Lasalocid, veterinary antibiotic, thallium (I) complex, structure, half sandwich

\section{Introduction}

Lasalocid A salt of sodium is one of the most commonly used veterinary antibiotics, where it has found wide spread application as an anticoccidial and to improve feed efficiency. The mechanism of action of lasalocid is clearly attributed to its ionophoric properties, because it has been reported to determine the influx of $\mathrm{Na}^{+}$in the cell of Gram positive and anaerobic bacteria, causing swelling, vacuolization, and death. At the origin of these processes, there is the property of forming lipophilic metal complexes, which can penetrate membranes and disrupt cation equilibria. 1,2

The molecular basis of this action are still debated; more specifically which of the oxygen atoms are directly involved in cation coordination. To date, this problem has been the object of many investigations almost invariably taking advantage of the concerted use of several 
experimental and computational techniques, which demonstrate both the relevance of the problem and its intrinsic difficulty. ${ }^{3}$

The identity of the various complexes formed according to the nature of the cation, to the solvent, and to the solution composition has been initially faced with optical spectroscopy and circular dichroism (CD), possibly using lanthanides as probes. ${ }^{4} \mathrm{X}$-ray diffraction data became available for several cations, among others $\mathrm{Na}^{+},{ }^{5}$ and $\mathrm{Ba}^{2+} .{ }^{2}$ Often, it has been observed that aggregates of different stoichiometry can take place, leading to the formation of sandwiches, where the cation occupies a cavity between two ligand molecules. ${ }^{3}$ Molecular dynamic calculations have been reported both in vacuo, ${ }^{7}$ and in solvent. ${ }^{8}$ Finally, there has recently appeared a series of papers on polyoxaalkyllasalocid esters/cation complexes making use of multinuclear NMR, IR, ESI-MS, and semiempirical methods. ${ }^{9}$ It has been proposed that antibacterial and fungicidal activity and also antitumor and anti- HIV-integrase inhibition of antibiotics lie in their ability to chelate the essential metals, which the micro-organisms need in their metabolism. ${ }^{9}$

\section{Results and Discussion}

We report the synthesis and structure of the first compound of a series of Lasalocid-thallium(I) complexes that is readily prepared as its pure stochioisomer ligand/metal (1/1). This new thallium (I) complex, deriving from lasalocid / thallium coordination, is obtained through two simple and economical synthetic methods (Scheme 1).

The reaction of lasalocid acid (1), with thallium salt $\left(\mathrm{Tl}_{2} \mathrm{CO}_{3}\right.$ or $\left.\mathrm{TlOH}\right)$ under ordinary atmosphere, with controlling $\mathrm{pH}(\mathrm{pH}>8)$, provides a stable coordination product (2), the thallium-lasalocid, which is characterised by $1 \mathrm{H}$ and ${ }^{13} \mathrm{C}$ NMR (Table 2).

The $\mathrm{Tl}$ atom can be coordinated by four, five or six neighbouring Oxygen atoms, leading to a variety of geometrical arrangements, such as tetrahedral, square pyramidal or trigonal bipyramidal, and octahedral. ${ }^{10-11}$

So it is difficult to give precise details about the site of coordination on the basis of NMR data (Tables 1 and 2). 


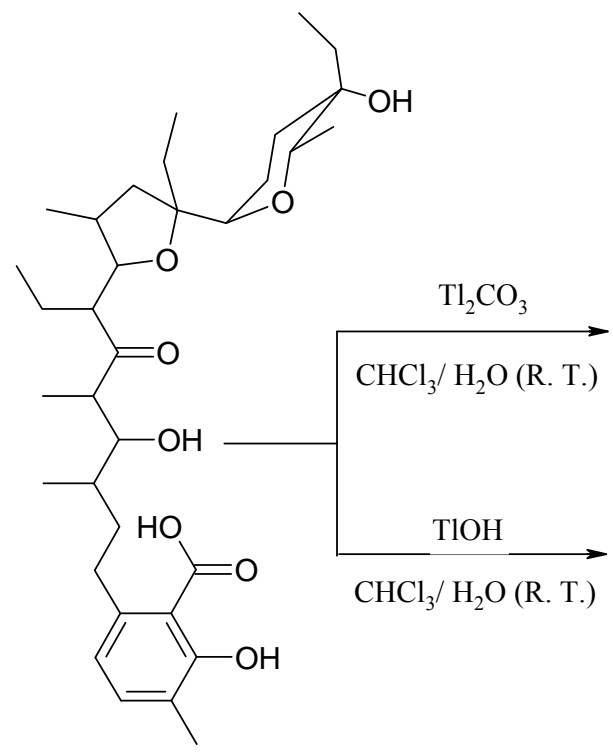

(1); Lasalocid Acid

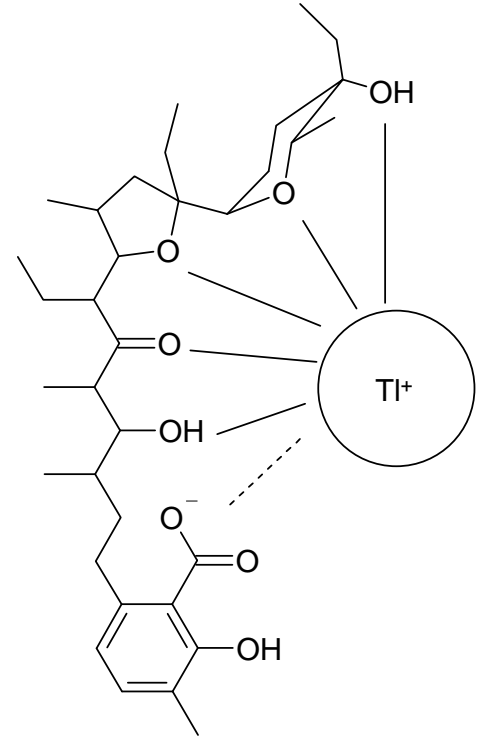

(2): [Thallium(I)-(Lasalocid anion)]

Scheme 1. Synthesis of [thalium(I)-(Lasalocid anion)] complex.

Table 1. ${ }^{1} \mathrm{H}$ and ${ }^{13} \mathrm{C}$ NMR data of complex (2)

\begin{tabular}{|c|c|c|c|c|c|c|c|c|}
\hline \multirow[b]{2}{*}{$\mathrm{Cx}$} & \multicolumn{2}{|c|}{${ }^{13} \mathrm{C}$ NMR ( ppm) } & \multirow[b]{2}{*}{$\mathrm{Hx}$} & \multicolumn{2}{|c|}{${ }^{1} \mathrm{H}$ NMR ( $\quad$ ppm) } & \multirow[b]{2}{*}{ JHx-Hy } & \multicolumn{2}{|c|}{${ }^{1}$ H NMR ( ppm) } \\
\hline & $\mathrm{CD}_{3} \mathrm{OD}$ & $\mathrm{CDCl}_{3}$ & & $\mathrm{CD}_{3} \mathrm{OD}$ & $\mathrm{CDCl}_{3}$ & & $\mathrm{CD}_{3} \mathrm{OD}$ & $\mathrm{CDCl}_{3}$ \\
\hline $\mathrm{C} 1$ & 177.7 & 175.9 & H5 & 7.06 & 7.01 & H5-H6 & 7.5 & 7.5 \\
\hline $\mathrm{C} 2$ & 116.9 & 116.3 & H6 & 6.58 & 6.51 & H8A-H8B & 11.2 & 12.5 \\
\hline $\mathrm{C} 3$ & 160.0 & 161.7 & H8A & 3.39 & 4.16 & H8A-H9A & 4.0 & 2.5 \\
\hline $\mathrm{C} 4$ & 124.1 & 123.4 & H8B & 2.33 & 2.14 & H8A-H9B & 11.2 & 12.5 \\
\hline $\mathrm{C} 5$ & 133.1 & 132.0 & H9A & 1.61 & 1.48 & H8B-H9A & 11.2 & 12.5 \\
\hline C6 & 121.6 & 119.7 & H9B & 1.61 & 1.48 & H8B-H9B & 5.6 & 5.6 \\
\hline $\mathrm{C} 7$ & 145.0 & 144.1 & $\mathrm{H} 10$ & 1.77 & 1.66 & H9A-H9B & 11 & 12.5 \\
\hline $\mathrm{C} 8$ & 33.8 & 32.6 & H11 & 4.42 & 4.41 & H9A-H10 & 7.5 & 4 \\
\hline C9 & 38.8 & 37.6 & H12 & 2.98 & 2.79 & H9B-H10 & 7.5 & 2 \\
\hline $\mathrm{C} 10$ & 35.0 & 33.7 & H14 & 2.75 & 2.48 & H10-H33 & 6.5 & 7.0 \\
\hline $\mathrm{C} 11$ & 71.6 & 70.4 & H15 & 4.15 & 4.15 & H10-H11 & 1.8 & 1.2 \\
\hline $\mathrm{C} 12$ & 50.0 & 48.1 & H16 & 2.35 & 2.24 & H11-H12 & 10.0 & 10.0 \\
\hline $\mathrm{C} 13$ & 218.5 & 217.0 & H17A & 2.02 & 1.88 & H12-H32 & 7.0 & 7.0 \\
\hline C14 & 57.1 & 56.4 & H17B & 1.5 & 1.38 & H14-H30A & 10.0 & 10.0 \\
\hline $\mathrm{C} 15$ & 86.5 & 84.9 & H19 & 3.9 & 3.72 & H14-H30B & 4.0 & 2.5 \\
\hline
\end{tabular}


Table 2. ${ }^{1} \mathrm{H}$ and ${ }^{13} \mathrm{C}$ NMR data of complex (2)

\begin{tabular}{|c|c|c|c|c|c|c|c|c|}
\hline \multirow[b]{2}{*}{ Carbon } & \multicolumn{2}{|c|}{${ }^{13} \mathrm{C}$ NMR ( ppm) } & \multirow[b]{2}{*}{$\mathrm{H}$} & \multicolumn{2}{|c|}{${ }^{1} \mathrm{H}$ NMR ( ppm) } & \multirow[b]{2}{*}{ JHx-Hy } & \multicolumn{2}{|c|}{${ }^{1} \mathrm{H}$ NMR ( $\left.\mathrm{ppm}\right)$} \\
\hline & $\mathrm{CD}_{3} \mathrm{OD}$ & $\mathrm{CDCl}_{3}$ & & $\mathrm{CD}_{3} \mathrm{OD}$ & $\mathrm{CDCl}_{3}$ & & $\mathrm{CD}_{3} \mathrm{OD}$ & $\mathrm{CDCl}_{3}$ \\
\hline $\mathrm{C} 16$ & 36.5 & 35.0 & $\mathrm{H} 20 \mathrm{~A}$ & 2.10 & 1.96 & H14-H15 & 4.0 & 2.5 \\
\hline $\mathrm{C} 17$ & 38.8 & 37.8 & $\mathrm{H} 20 \mathrm{~B}$ & 1.63 & 1.57 & H15-H16 & 10.0 & 10.4 \\
\hline $\mathrm{C} 18$ & 89.2 & 87.9 & $\mathrm{H} 21 \mathrm{~A}$ & 1.81 & 1.78 & H16-H17A & 8.0 & 5.0 \\
\hline C19 & 72.1 & 69.7 & $\mathrm{H} 21 \mathrm{~B}$ & 1.81 & 1.78 & H16-H17B & 11.0 & 10.5 \\
\hline $\mathrm{C} 20$ & 20.8 & 19.8 & $\mathrm{H} 23$ & 3.97 & 3.84 & H16-H29 & 6.5 & 6.5 \\
\hline $\mathrm{C} 21$ & 30.6 & 29.4 & $\mathrm{H} 24$ & 1.32 & 1.19 & H17A-H17B & 12.6 & 12.6 \\
\hline $\mathrm{C} 22$ & 72.9 & 71.6 & $\mathrm{H} 25 \mathrm{~A}$ & 1.92 & 1.78 & H19-H20A & 107.0 & 11.2 \\
\hline $\mathrm{C} 23$ & 78.0 & 77.4 & $\mathrm{H} 25 \mathrm{~B}$ & 1.5 & 1.26 & H19-H20B & 3.2 & 1.6 \\
\hline $\mathrm{C} 24$ & 14.1 & 13.6 & $\mathrm{H} 26$ & 0.94 & 0.81 & H20A-H20B & 14.0 & 12.6 \\
\hline $\mathrm{C} 25$ & 32.6 & 31.6 & $\mathrm{H} 27 \mathrm{~A}$ & 1.63 & 1.51 & $\mathrm{H} 20 \mathrm{~A}-\mathrm{H} 21 \mathrm{~A}$ & 11 & 9.0 \\
\hline $\mathrm{C} 26$ & 6.8 & 6.5 & $\mathrm{H} 27 \mathrm{~B}$ & 1.53 & 1.40 & $\mathrm{H} 20 \mathrm{~A}-\mathrm{H} 21 \mathrm{~B}$ & 5 & 3.0 \\
\hline $\mathrm{C} 27$ & 31.7 & 30.3 & $\mathrm{H} 28$ & 1.03 & 0.97 & $\mathrm{H} 20 \mathrm{~B}-\mathrm{H} 21 \mathrm{~A}$ & 6 & 4.5 \\
\hline $\mathrm{C} 28$ & 9.8 & 9.5 & $\mathrm{H} 29$ & 1.17 & 1.03 & H20B-H21B & - & - \\
\hline $\mathrm{C} 29$ & 16.2 & 16.2 & $\mathrm{H} 30 \mathrm{~A}$ & 2.02 & 1.96 & $\mathrm{H} 21 \mathrm{~A}-\mathrm{H} 21 \mathrm{~B}$ & 12 & 12.6 \\
\hline $\mathrm{C} 30$ & 17.1 & 15.8 & $\mathrm{H} 30 \mathrm{~B}$ & 1.53 & 1.30 & H23-H24 & 7.0 & 7.0 \\
\hline $\mathrm{C} 31$ & 13.1 & 12.5 & H31 & 0.92 & 0.8 & H25-H26 & 7.0 & 7.0 \\
\hline $\mathrm{C} 32$ & 13.7 & 13.4 & $\mathrm{H} 32$ & 1.00 & 0.93 & H25A-H25B & - & 14.0 \\
\hline $\mathrm{C} 33$ & 12.8 & 12.6 & $\mathrm{H} 33$ & 0.91 & 0.84 & H27-H28 & 6.8 & 7.0 \\
\hline C34 & 15.8 & 15.6 & H34 & 2.22 & 2.21 & H27A-H27B & - & 14.0 \\
\hline
\end{tabular}

\section{Crystallographic study}

The crystallographically complementary coordinating aryl group is located on a second lasalocid (Lasa 2). These two lasalocid ligands (Lasa 1 and Lasa 2) are not tied together by a threedimensional hydrogen-bonding network as it was observed previously by Akkurt et al. in the case of $\left[\mathrm{Sr}(\operatorname{Lasa})_{2}\left(\mathrm{H}_{2} \mathrm{O}\right)\right]$ as it is reported. ${ }^{12}$ These monomeric units are not stacked by any Van der Waals forces between the coordination spheres (Figures 1 and 2). 


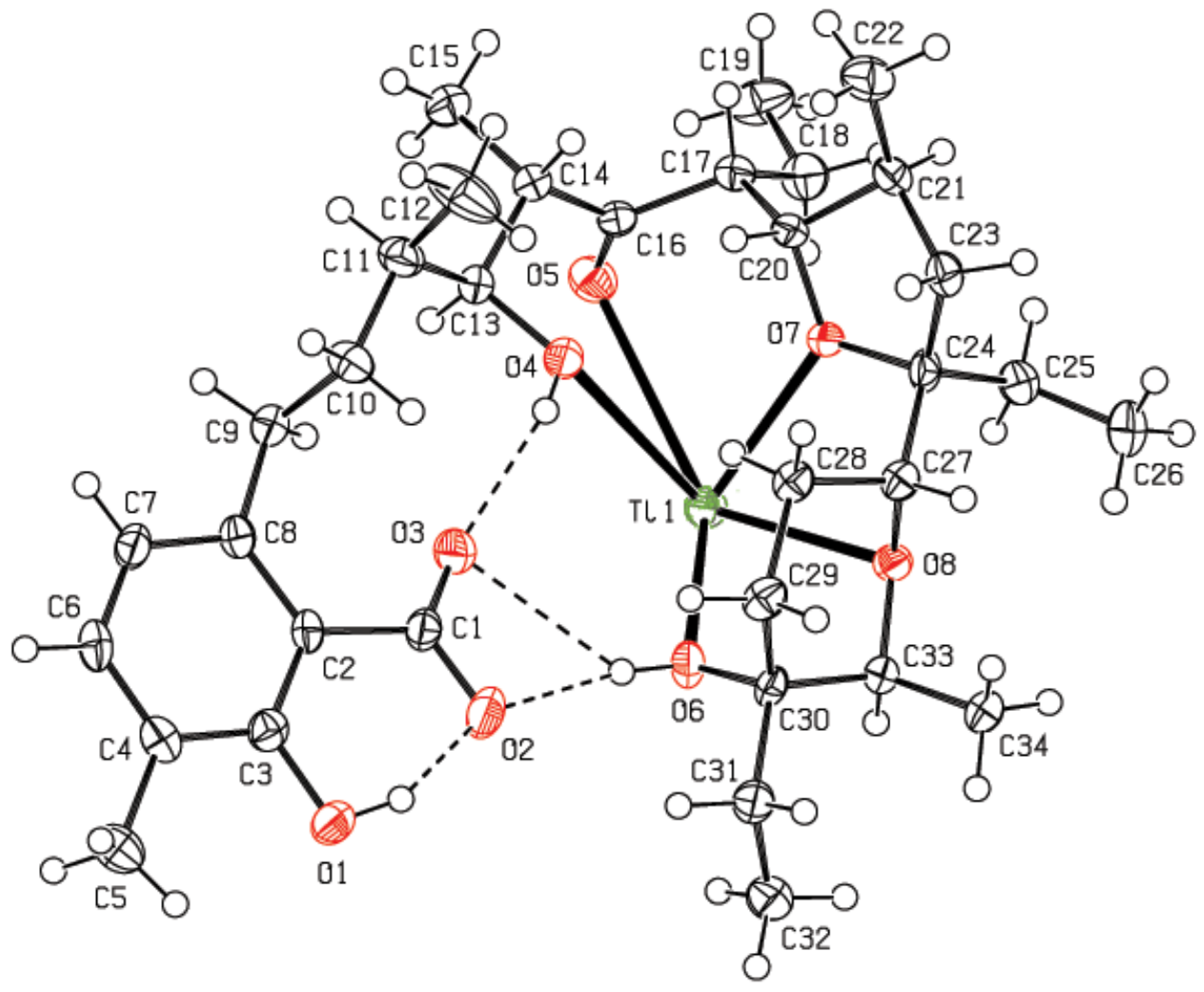

Figure 1. An ORTEP view of the title compound, with the atom-numbering scheme. Displacement ellipsoids are drawn at the $50 \%$ probability level.

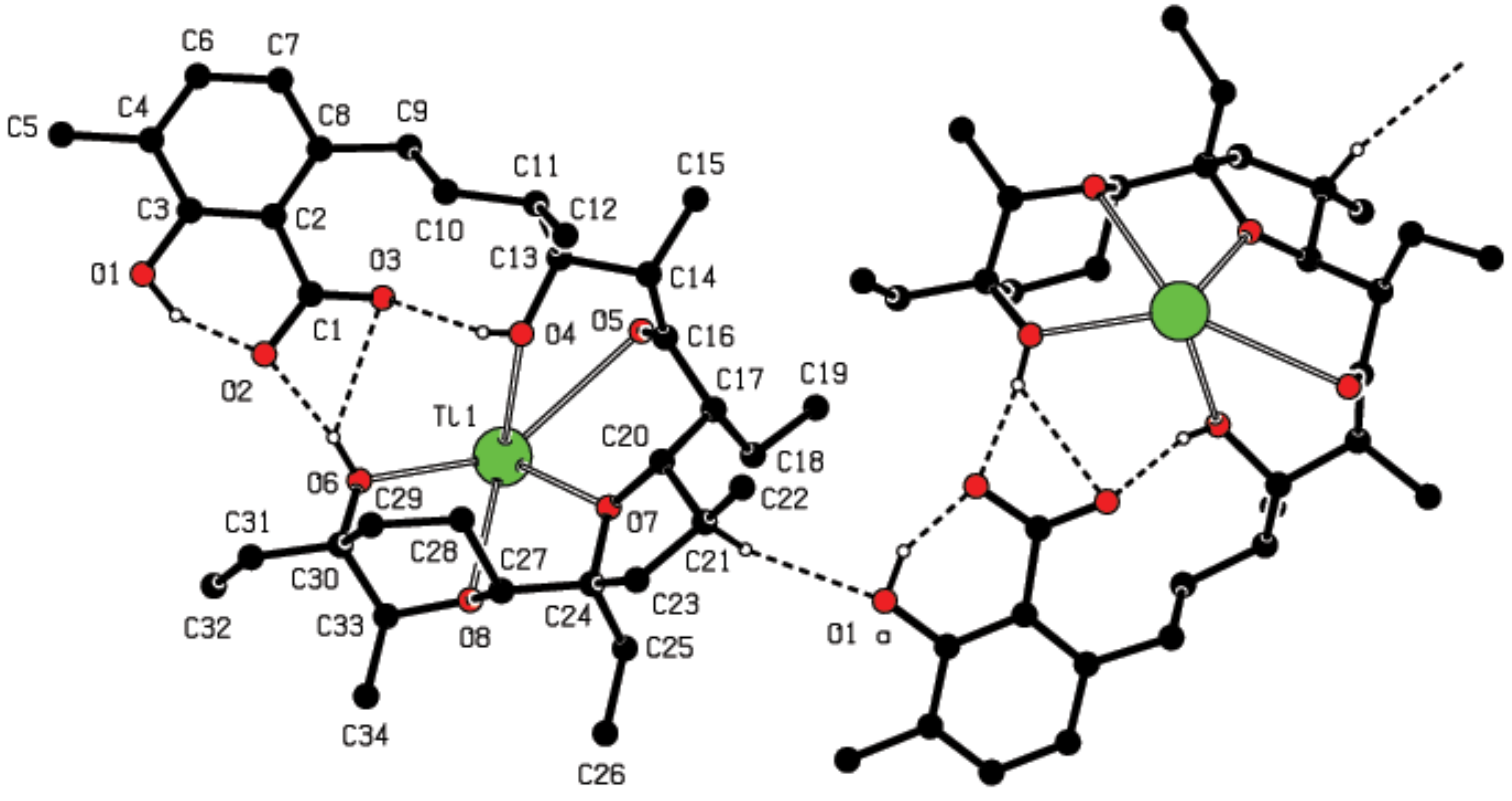

Figure 2. A view of the hydrogen bonding of the title compound. $H$ atoms not involved in hydrogen bonding have been omitted for clarity. 
Since the coordination properties of the two neighbour molecules of lasalocid ligands are not different, it is concluded that the two lasalocid ligands are individually but simultaneously coordinated to two $\mathrm{Tl}$ atoms (Figures 3 ).
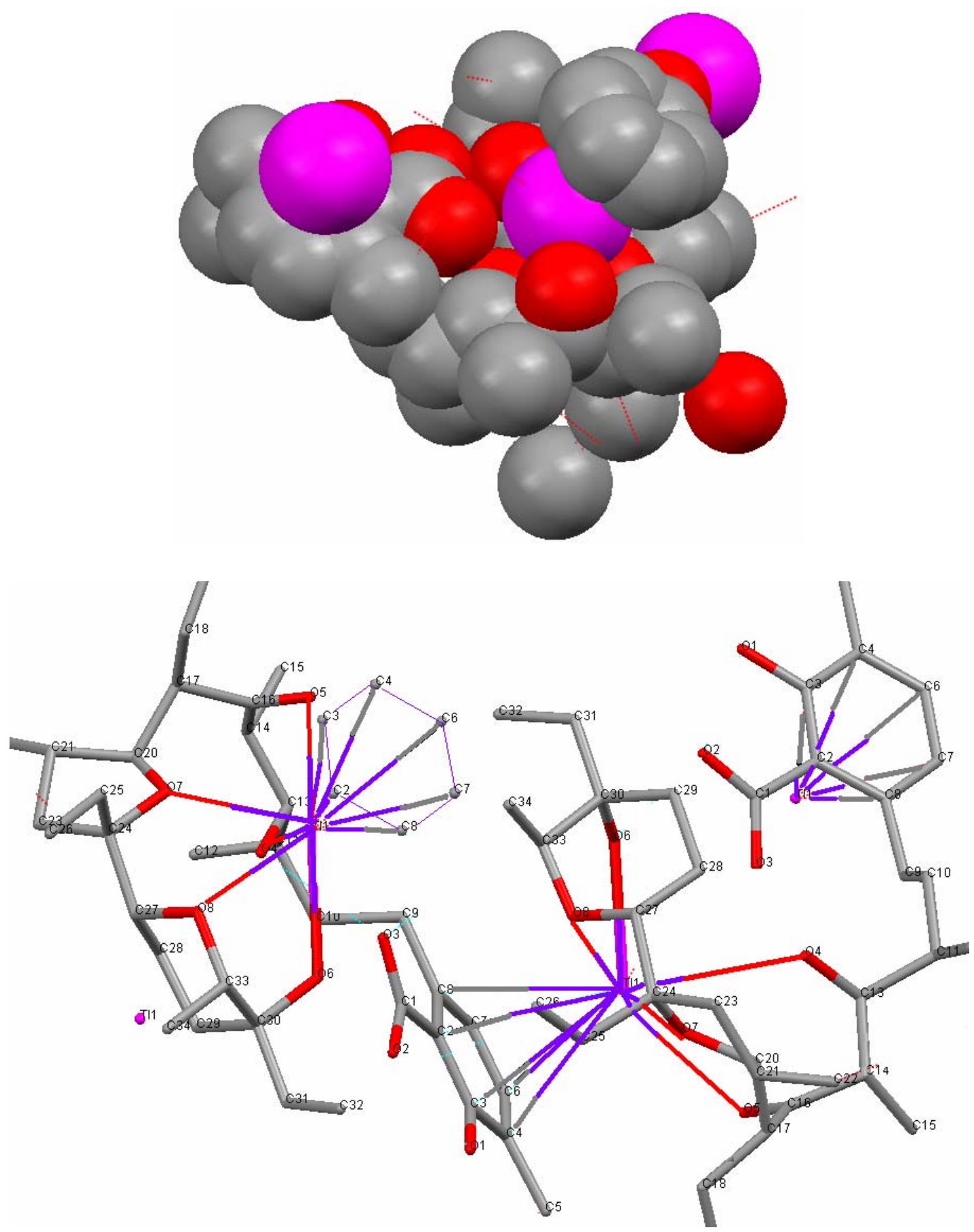

Figures 3. A view of the aryl-Thallium and Thallium-Oxygen bonding of the title compound. This figure was obtained by displaying packing and short contacts. 
To have a clear idea about the coordinative aspect of the lasalocid ligands leading to a polymeric aspect of this complex, the view for the complex [Tl(Lasa) $]_{\mathrm{n}}$ has been added here as shown in Figure 4.

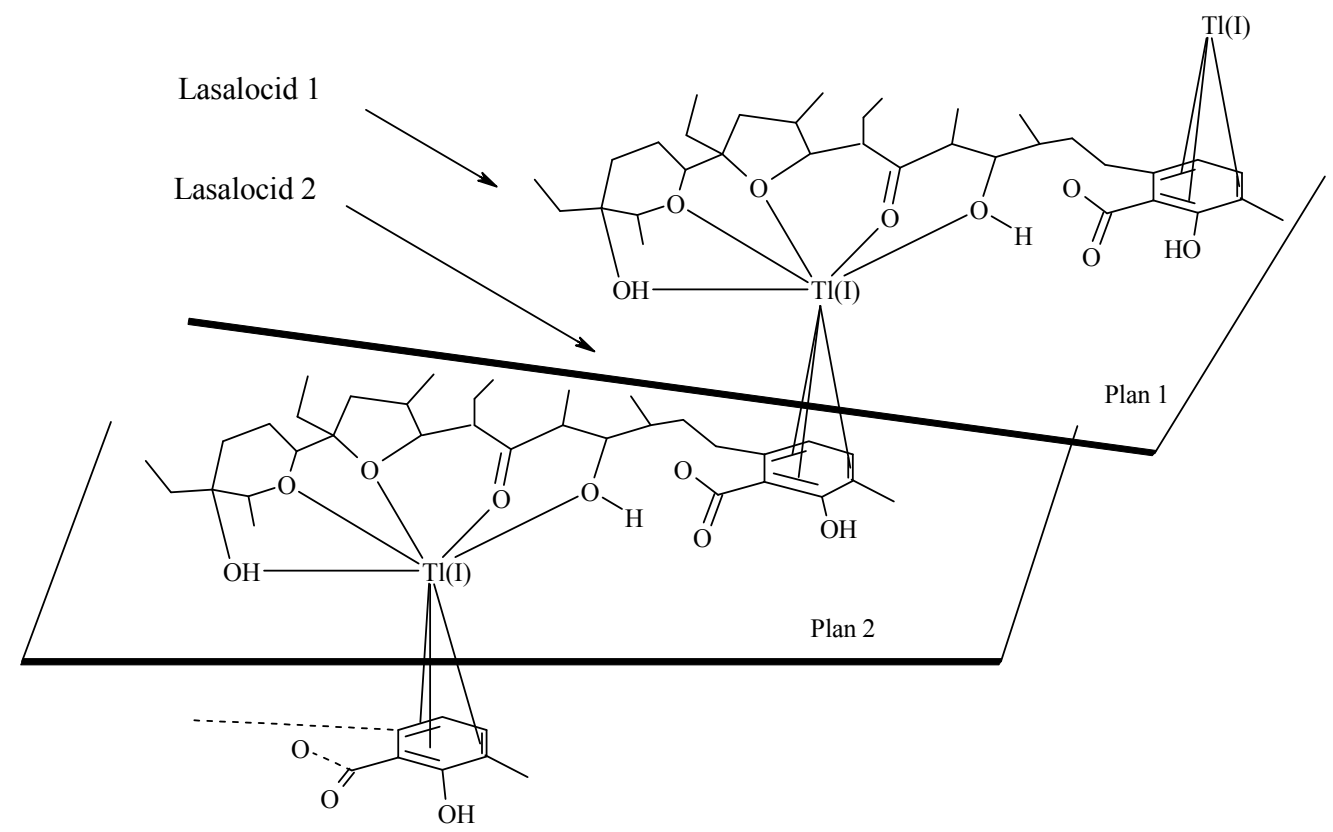

Figure 4. Polymeric aspect of $\{[\text { thallium-(lasalocid anion) }]\}_{\mathrm{n}}$ complex.

This complex between thallium(I) and antibiotic lasalocid ligand is a polymer. It is based on dimeric, non centrosymmetric $\mathrm{Tl}_{2}$ (Lasalocid) $)_{2}$ units without $\mu_{2}$-bridging carboxylic groups resulting in $\mathrm{Tl} \cdots \mathrm{Tl}$ separations of 7.65-7.70 $\AA$. These dimeric units are further linked to form infinite coordination polymers. In bis [(lasalocid anion)-thallium(I)] (1) are adjacent units are held together by secondary Tl-(phenyl) p-interactions resulting in a crystal organization which can be described as half sandwich, infinite two-dimensional polymers. Another characteristic structural motif is the tendency of the thallium ion to only use less than one hemisphere to coordinate ligands. This "half-nakedness" is due to the stereochemically active inert pair $\left(6 \mathrm{~s}^{2}\right)$, which thus plays a prominent role in controlling the structures of these compounds. ${ }^{17} \mathrm{The}^{+}$ cations are in approximate pyramidal geometries, with five oxygen donor atoms in the basal plane and the stereoactive lone pair occupying the apex position of the pyramid. There are, on the naked side of the metal ions, relatively large spaces in nonpolar environments provided by neighboring phenyl groups. The distances between the planes of the phenyl rings and the $\mathrm{Tl}^{+}$ cation are in the range 3.43-3.50 $\AA$, indicating that $\mathrm{Tl}^{+}$-phenyl $\eta^{6}$-interactions are important in the crystal organization. 


\section{Conclusions}

In conclusion, we describe here what is to our knowledge the first solid-state structure obtained with a thallium-lasalocid complex. The tetra-butyl ammonium salt of lasalocid is able to form a stable 1:1 (ligand:metal) complex with monovalent cations such as thallium(I). The structure of this complex is completely different with the respective complexes with other monovalent cations and divalent cations $\left(\mathrm{Mg}^{2+}\right.$ and $\left.\mathrm{Ca}^{2+}\right) \cdot{ }^{15}$

In contrast to Sr-lasalocid complex, the study of in vitro biological activity of the TlLasalocid on fungus F. oxysporum, at Oujda, shows that this compound is not biologically active. This contrast in this biological antifungal screening for the same ligand containing different metals is very important for future agricultural applications and deserves to be extended to a wide series of transition metals [Ru(II), $\mathrm{Co}(\mathrm{II}), \mathrm{Fe}(\mathrm{II})]$.

\section{Experimental Section}

\section{Preparation of complex (2)}

Method (A). A solution of lasalocid free acid (1 mmole, prepared in $20 \mathrm{~mL}$ of $\mathrm{CHCl}_{3}$ was stirred with $0.1 \mathrm{M}$ aqueous $\mathrm{Tl}_{2} \mathrm{CO}_{3}\left(0.7 \mathrm{mmole}\right.$, prepared in $30 \mathrm{~mL}$ of $\left.\mathrm{H}_{2} \mathrm{O}\right)$. The mixture was stirred at $20{ }^{\circ} \mathrm{C}$ for 2 hours. The organic layer was then dried over anhydrous $\mathrm{Na}_{2} \mathrm{SO}_{4}$, filtered and evaporated. The solid residue was dissolved in $\mathrm{MeOH}$ and the solvent was left to evaporate at $20{ }^{\circ} \mathrm{C}$ for 1 week in the dark. White crystals obtained proved suitable for X-ray analysis $(83 \%$ Yield).

Method (B). A solution of lasalocid free acid (1 mmole, prepared in $20 \mathrm{~mL}$ of $\mathrm{CHCl}_{3}$ was stirred with $0.1 \mathrm{M}$ aqueous $\mathrm{TlOH}\left(1.2 \mathrm{mmole}\right.$, prepared in $30 \mathrm{~mL}$ of $\left.\mathrm{H}_{2} \mathrm{O}\right)$. The mixture was stirred at $20{ }^{\circ} \mathrm{C}$ for 3 hours. The organic layer was then dried over anhydrous $\mathrm{Na}_{2} \mathrm{SO}_{4}$, filtered and evaporated. The solid residue was dissolved in $\mathrm{MeOH}$ and the solvent was left to evaporate at $20{ }^{\circ} \mathrm{C}$ for 1 week in the dark. White crystals obtained proved suitable for X-ray analysis $(85 \%$ Yield).

The complex (2) is characterised by ${ }^{1} \mathrm{H}$ and ${ }^{13} \mathrm{C}$ NMR by using Bruker $\mathrm{AC} 400 \mathrm{MHz}$ spectrometer. The purity of product (2) is excellent $(99.5 \%)$.

Crystal structure analysis. The crystal structure of the title compound, $\operatorname{Tl}\left(\mathrm{C}_{34} \mathrm{H}_{53} \mathrm{O}_{8}\right)$, has been determined at room temperature. Diffraction data were collected using a Bruker SMART APEXII CCD diffractometer system, using graphite-monochromated MoK $\alpha$ radiation. The crystallographic details are given in Table 1 . The structure was solved by direct methods by using SIR-97 program and refined by least-squares on Fobs ${ }^{2}$ and by using SHELXL-97 programs. O1, $\mathrm{O} 4$ and $\mathrm{O} 6 \mathrm{H}$ atoms were located in a difference Fourier map and refined freely. All other $\mathrm{H}$ atoms were located in calculated positions and treated as riding on their parent 
atoms, with $\mathrm{C}-\mathrm{H}=0.96\left(\mathrm{CH}_{3}\right), 0.97\left(\mathrm{CH}_{2}\right)$ or $0.98 \AA(\mathrm{CH})$, and with $\mathrm{U}_{\text {iso }}(\mathrm{H})=1.5 \mathrm{U}_{\text {eq }}\left(\mathrm{CH}_{3}\right)$ or 1.2 $\mathrm{U}_{\mathrm{eq}}\left(\mathrm{CH}_{2}, \mathrm{CH}\right)$.

A displacement ellipsoid plot with the atomic numbering scheme of the title compound is shown in Figure 2; with selected bond lengths, bond and torsion angles angles, and hydrogen-bonding geometry in Tables 2 and 3 , respectively.

The title complex, $\left[\mathrm{Tl}\left(\mathrm{C}_{34} \mathrm{H}_{53} \mathrm{O}_{8}\right)\right]$, crystallizes with five-coordinated $\mathrm{Tl}$ atom three dimensionally interconnected into a polymeric structure. The thallium atom shows a distorted trigonalpyramidal coordination geometry formed by five $\mathrm{O}$ atoms. The mean $\mathrm{Tl}-\mathrm{O}$ bond lengths 2.9352(3) $\AA$. The geometric parameters of the present structure agree with those previously studied at room temperature but with significantly improved precision.

Within the ligands, other geometric parameters $(\mathrm{C}-\mathrm{O}$ and $\mathrm{C}-\mathrm{C}$ distances, and $\mathrm{O}-\mathrm{C}-\mathrm{O}$ and $\mathrm{O}-\mathrm{C}-\mathrm{C}$ angles) all lie in the expected ranges. ${ }^{13}$ The crystal polymeric structure is stabilized by the metal-aryl Tl(i)---Aryl (Lasa $\mathrm{i}+1$ ) and $\mathrm{Tl}(\mathrm{i}+1)$---Aryl (Lasa $\mathrm{i}+2$ ) [ ring-metal interactions with $\pi$-Ph $\leq 4 \AA$ - symmetry code: $1-\mathrm{x}, 1 / 2+\mathrm{y}, 1 / 2-\mathrm{z}$ ] type-half sandwich bonding interactions (Table 2).

The molecular and crystal structures are stabilized by the $\mathrm{O}-\mathrm{H}^{\mathrm{*}} \mathrm{O}$ and $\mathrm{C}-\mathrm{H}^{-*} \mathrm{O}$ typehydrogen bonding interactions (Table 5, Figure 2).

Table 3. Crystal and experimental data.

Formula: $\mathrm{C}_{34} \mathrm{H}_{53} \mathrm{O}_{8} \mathrm{~T}_{1}$

Formula weight $=794.14$

Crystal system: orthorhombic

Space group: $\mathrm{P} 2{ }_{1} 2_{1} 2_{1} \quad$ (No. 19); $Z=4$

$a=11.211(3) \AA$

$b=13.684(4) \AA$

$c=22.690(7) \AA$

$V=3480.9(17) \AA^{3}$

$D_{\mathrm{x}}=1.515 \mathrm{~g} \mathrm{~cm}^{-3}$

$\mu\left(\mathrm{MoK}_{\alpha}\right)=4.687 \mathrm{~cm}^{-1}$

$T=150 \mathrm{~K}$

$F\left(\begin{array}{lll}0 & 0 & 0\end{array}\right)=1608$

Crystal size $=0.13 \times 0.17 \times 0.19 \mathrm{~mm}$

Radiation: $\mathrm{MoK}_{\alpha}$

$R=0.0275$

$R_{\mathrm{W}}=0.0557$

No. of unique data measured $=10170$

No. of observed data with $[I \geq 2 \sigma(I)]=9327$

No. of parameters $=400$

Goodness-of-fit $=1.01$

$(\Delta \rho)_{\max }=0.94 \mathrm{e}^{-3}$ 
$(\Delta \rho)_{\min }=-0.54 \mathrm{e}^{-3}$

Measurements: Bruker SMART APEX-II CCD diffractometer ${ }^{14}$

Structure determination: $\underline{\text { SIR97 }}^{15}$

Refinement: full matrix least-squares SHELXL-97 $7^{16}$

Note: CCDC 682527 contains the supplementary crystallographic data for this paper. These data can be obtained free of charge from The Cambridge Crystallographic Data Centre via www.ccdc.cam.ac.uk/data_request/cif.

Table 4. Selected bond lengths $(\AA)$, bond and torsion angles $\left({ }^{\circ}\right)$

\begin{tabular}{cccc}
\hline T11 - O4 & $3.320(3)$ & T11 - O7 & $2.737(2)$ \\
T11 - O5 & $3.158(2)$ & T11 - O8 & $2.825(2)$ \\
T11 - O6 & $2.636(2)$ & O6 - C30 & $1.433(4)$ \\
O1 - C3 & $1.365(5)$ & O7 - C20 & $1.439(4)$ \\
O2 - C1 & $1.277(4)$ & O7 - C24 & $1.467(4)$ \\
O3 - C1 & $1.250(4)$ & O8 - C27 & $1.439(4)$ \\
O4 - C13 & $1.430(4)$ & O8 - C33 & $1.444(4)$ \\
O5 - C16 & $1.205(4)$ & T11 - C6 ${ }^{i}$ & $3.501(4)$ \\
T11 - C2 & $3.439(3)$ & T11 - C7 & $3.482(4)$ \\
T11 - C3 & $3.472(4)$ & T11 -C $8^{i}$ & $3.453(3)$ \\
T11 - C4 & $3.491(4)$ & & \\
O6 - T11 - O7 & $106.82(6)$ & T11 - O7 - C24 & $117.10(17)$ \\
O6 - T11 - O8 & $60.69(6)$ & C20 - O7 - C24 & $109.4(2)$ \\
O7 - T11 - O8 & $61.55(6)$ & T11 - O8 - C27 & $106.93(19)$ \\
T11 - O6 - C30 & $123.48(16)$ & T11 - O8 - C33 & $109.28(16)$ \\
T11 - O7 - C20 & $129.36(16)$ & O6 - T11 - O8 - C27 & $-99.89(19)$ \\
O7 - T11 - O6 - C30 & $-31.9(2)$ & O6 - T11 - O8 - C33 & $24.43(17)$ \\
O8 - T11 - O6 - C30 & $10.38(19)$ & O7 - T11 - O8 - C27 & $33.08(17)$ \\
O6 - T11 - O7 - C20 & $-110.0(2)$ & O7 - T11 - O8 - C33 & $157.41(19)$ \\
O6 - T11 - O7 - C24 & $44.46(19)$ & T11 - O6 - C30 - C29 & $77.0(3)$ \\
O8 - T11 - O7 - C20 & $-151.8(2)$ & T11 - O6 - C30 -C31 & $-162.07(18)$ \\
O8 - T11 - O7 - C24 & $2.66(17)$ & & \\
\hline
\end{tabular}

Symmetry Code: $i=1-\mathrm{x},-1 / 2+\mathrm{y}, 1 / 2-\mathrm{z}$ 
Table 5. Hydrogen-bonding geometry $\left(\AA,{ }^{\circ}\right)$

\begin{tabular}{|c|c|c|c|c|}
\hline D-H"A A & D-H & $\mathrm{H} \cdots \mathrm{A}$ & D...A & D-H”A \\
\hline $\mathrm{O} 1-\mathrm{HO} 1 \ldots \mathrm{O} 2$ & $0.89(4)$ & $1.65(4)$ & $2.469(4)$ & $152(4)$ \\
\hline $\mathrm{O} 4-\mathrm{HO} 4 \ldots \mathrm{O} 3$ & $0.67(3)$ & $2.05(3)$ & $2.684(4)$ & $159(4)$ \\
\hline O6-HO6_... 2 & $0.89(4)$ & $1.86(4)$ & $2.738(3)$ & $170(3)$ \\
\hline O6- & $0.89(4)$ & $2.49(4)$ & $3.121(3)$ & $129(3)^{\prime}$ \\
\hline C5-H5A...O1 & 0.96 & 2.33 & $2.794(5)$ & 109 \\
\hline С9-H9B...O3 & 0.97 & 2.28 & $2.802(4)$ & 113 \\
\hline C10-H10B...O4 & 0.97 & 2.57 & $2.935(5)$ & 102 \\
\hline $\mathrm{C} 20-\mathrm{H} 20 \ldots \mathrm{O} 4$ & 0.98 & 2.51 & $3.195(4)$ & 127 \\
\hline C28-H28A...O4 & 0.97 & 2.43 & $3.373(4)$ & 163 \\
\hline С28-H28A...O7 & 0.97 & 2.50 & $2.900(4)$ & $104^{\prime}$ \\
\hline $\mathrm{C} 21-\mathrm{H} 21 \ldots \mathrm{OO} 1^{i}$ & 0.98 & 2.51 & $3.321(4)$ & 140 \\
\hline
\end{tabular}

Symmetry Code: $i=3 / 2-\mathrm{x}, 1-\mathrm{y},-1 / 2+\mathrm{z}$

\section{Acknowledgements}

The authors acknowledge Professor Georges Jeminet and the "Agence universitaire de la francophonie", for sending us the ionophores ligands (lasalocid, monensin and calcimycin). This work was also supported by the PGR-BH-2005 and PROTARS I-BH-2000 Grants from the Ministry of National Education of Morocco.

\section{References}

1. Crandall, L. W.; Hamill, R. L. In Kirk-Othmer Encyclopedia of Chemical Technology, $4^{\text {th }}$ Edn.; Wiley: New York, 1992; Vol. 3, pp 306.

2. Lindsay, D. S.; Blagburn, B. L. In Veterinary Pharmacology and Therapeutics, Adams, H. R., Ed.; Blackwell Publishing Professional: Ames, IA, 2001; pp 992.

3. Lindoy, L. F. Coord.Chem. Rev. 1996, 148, 349.

4. (a) Tsukube, H.; Takeishi, H.; Yoshida, Z. Inorg. Chim. Acta 1996, 251, 1. (b) AguilarCaballos, M. P.; Goemez-Hens, A.; Perez-Bendito, D. Talanta 1999, 48, 209.

5. Schmidt, P. G.; Wang, A. H. J.; Paul, I. C. J. Am. Chem. Soc. 1974, 96, 6189.

6. Johnson, S. M.; Herrin, J.; Liu, S. J.; Paul, I. C. J. Am. Chem. Soc. 1970, 92, 4428.

7. (a) Malfreyt, P.; Lyazghi, R.; Dauphin, G.; Pascal, Y; Juillard, J. J. Chem. Soc. Perkin Trans.2 1996, 85, 1971. (b) Tissier, M.; Mousset, G.; Juillard, J. J. Chem. Soc. Faraday Trans. 1989, 2, 1337.

8. Lyazghi, R.; Cuer, A.; Dauphin, G.; Juillard, J. J. Chem. Soc. Perkin Trans 2 1992, 35. 
9. (a) Pankiewicz, R.; Pawlowska, A.; Schroeder, G.; Przybylski, P.; Brzezinski, B.; Bartl, F. J. Mol. Struct. 2004, 694, 55. (b) Pankiewicz, R.; Pawlowska, A.; Schroeder, G.; Przybylski, P.; Brzezinski, B.; Bartl, F. J. Mol. Struct. 2004, 694, 155. (c) Pankiewicz, R.; Schroeder, G.; Przybylski, P.; Brzezinski, B. J. Mol. Struct. 2005, 733, 155. (d) Pankiewicz, R.; Schroeder, G.; Przybylski, P.; Brzezinski, B. J. Mol. Struct. 2005, 733, 217.

10. Abdi, M.; Zouari, F.; Chaabouni, S.; Elaoud, Z.; Ben Salah, A. Phase Transitions 2003, 76, 723.

11. Linden, A.; Petridis, A.; James, B. D. Helv. Chim. Acta 2003, 86, 711.

12. Akkurt, M.; Yıldırım, S. Ö. ; Melhaoui, A.; Khardli, F-Z.; Mimouni, M.; McKee, V.; Ben Hadda, T. Arkivoc 2007, (xvi), 314.

13. Allen, F. H.; Kennard, O.; Watson, D. G.; Brammer, L.; Orpen, A. G.; Taylor, R. J. Chem. Soc. Perkin Trans. 2 1987, 2, S1.

14. Bruker, 2005, APEX2 (Version 2.1) and SAINT (Version 7.23A). Bruker AXS Inc., Madison, Wisconsin, USA.

15. Altomare, A.; Burla, M. C.; Camalli, M.; Cascarano, G.; Giacovazzo, C.; Guagliardi, A.; Moliterni, A. G. G.; Polidori, G. L.; Spagna, R. J. Appl. Crystallogr. 1999, 32, 115.

16. Sheldrick, G.M., 1997, SHELXL97. Program for the Refinement of Crystal Structures, University of Göttingen, Germany.

Kristiansson, O. Europ. J. Inorg. Chem. 2002, 9, 2355. 